Results Semen assessments were obtained for 502 men. This group was representative of the general population regarding social class, education and geography. The median sperm concentration of samples was $48 \times 10^{6} / \mathrm{ml}$, but after adjustment to a mean abstinence of 4 days, $64 \times 10^{6} / \mathrm{ml}$. In these adjusted data, "low" sperm counts (below $20 \times 10^{6} / \mathrm{ml}$ ) were found in $18 \%$ of men ( $95 \%$ CI $15 \%$ to $21 \%$ ). However, the prevalence of "low" sperm counts showed no trend across the 10-year range of birth years.

Conclusion This first report of sperm concentration in a random sample of a general population shows that nearly a fifth of men had poor semen quality. Further work is required to clarify the fertility relevance of a single low sperm concentration when there is no imposition of abstinence prior to sample, and to understand cause of the fertility deficit found in many survey participants.

\section{SP4-26 BURDEN OF TOXIC METAL EXPOSURE AMONG SCHOOL- AGED CHILDREN IN UNITED ARAB EMIRATES}

doi:10.1136/jech.2011.142976p.20

${ }^{1} \mathrm{~S}$ Yousef, ${ }^{*}{ }^{1} \mathrm{~A}$ Adem, ${ }^{2} \mathrm{~V}$ Eapen, ${ }^{1} \mathrm{~T}$ Zoubeidi, ${ }^{1} \mathrm{M}$ Kosanovic, ${ }^{1} \mathrm{~A}$ A Mabrouk. ${ }^{1} \mathrm{U} A E$ University, Al Ain, Abu Dhabi, United Arab Emirates; ${ }^{2}$ University of New South Wales, New South Wales, Australia

Background Environmental toxic metal exposure may adversely affect children's development and behaviour. Data are lacking about heavy metal exposure in children in UAE and Gulf countries.

Objectives To determine blood concentrations of 12 heavy metals in school-age children in Al Ain City, UAE.

Methods It was a cross sectional study. One hundred and forty seven subjects were selected from nine elementary schools. The mean age was 8.4 years ( $S D \pm 2$ years). ICP-MS instrument was used to determine the metal concentration. Data analysis was performed using the SPSS.

Results The (mean \pm SD) blood level for study children $(n=146)$ of lead was $25.86 \pm 13.06 \mathrm{ppb}$, cadmium $0.31 \pm 0.25 \mathrm{ppb}$, arsenic $10.74 \pm 4.71 \mathrm{ppb}$, mercury $1.39 \pm 1.16 \mathrm{ppb}$, manganese $1.85 \pm 1.09$ ppb, nickel 9.18 $\pm 8.23 \mathrm{ppb}$, zinc $3731 \pm 1752 \mathrm{ppb}$, chromium $2.10 \pm 1.53 \mathrm{ppb}$, cobalt $0.65 \pm 0.40 \mathrm{ppb}$, copper $1064 \pm 403 \mathrm{ppb}$, molybdenum $1.59 \pm 1.25 \mathrm{ppb}$, and antinomy $0.60 \pm 0.63 \mathrm{ppb}$.

Conclusions Reference values for the trace metals vary markedly; especially due to sampling, age, diet, exposure differences and analytical techniques used. In this study, the mean blood lead was below the CDC's recommended level of concern $(>10 \mu \mathrm{g} / \mathrm{dl})$ and with cadmium, mercury and chromium were comparable with similar studies elsewhere; manganese and zinc were slightly lower; copper and molybdenum were slightly higher while arsenic and cobalt much higher. Blood screening and surveillance linked to appropriate public health interventions is strongly recommended for UAE.

\section{SP4-27 HIGH PREVALENCE OF ESCHERICHIA COLI AND HUMAN ADENOVIRUS IN WATER, MUSSELS AND YOUNG CHILDREN WITH ACUTE GASTROENTERITIS LIVING IN MANGROVE REGION}

doi:10.1136/jech.2011.142976p.21

R Keller, ${ }^{*}$ J Justino, S T Cassini, E Maciel. Federal University of Espirito Santo, Vitória, Espirito Santo, Brazil

Introduction Several studies have shown that many aquatic ecosystems are often contaminated with pathogenic microorganisms through the discharge of untreated or partially treated sewage. The maintenance of water quality is a major challenge for governments with direct consequences on the health of the environment and the population. Mangrove is an important source of livelihood for fishermen living in the region of Vitória, ES, Brazil. In the last years high numbers of gastroenteritis cases have been reported in this region suggesting an association between the consumption or handling of contaminated water and mussels and the development of gastrointestinal diseases. The aim of this study was to investigate the sanitary quality of water and mussels and to evaluate an association of gastroenteritis cases and the presence of adenovirus and bacterial indicators of fecal pollution in these samples.

Methods Feces of children from 0 months to 12 years living in the areas of study and diagnosed with gastroenteritis are collected and evaluated for the presence of adenovirus. Water and mussels are sampled monthly and analysed for adenovirus by PCR and nestedPCR; total coliforms and $E$ coli were detected using the Total Coliform/E coli Enzyme substrate test (Colilert $($ ) $)$.

Results All water samples and mussels analysed were positive for $E$ coli. Adenovirus genome was detected in $76 \%$ of water samples and $100 \%$ of mussel samples collected.

Conclusion These data shows that this area is highly contaminated with domestic sewage and indicates that consumption of seafood may be associated with cases of gastroenteritis reported in the region.

\section{SP4-28 CHILDBEARING DURING ADOLESCENCE AND OFFSPRING MORTALITY: COMPARISON OF THREE POPULATION BASED COHORTS IN SOUTHERN BRAZIL}

doi:10.1136/jech.2011.142976p.22

${ }^{1}$ M C Restrepo, ${ }^{*}$ A M B Menezes, ${ }^{1}$ I da Silva Santos, ${ }^{1}$ B L Horta, ${ }^{2}$ F C Barros, ${ }^{1} \mathrm{C}$ G Victora. 'Universidade Federal de Pelotas, Pelotas, Rio Grande do Sul, Brazil, ${ }^{2}$ Universidade Católica de Pelotas, Pelotas, Rio Grande do Sul, Brazil

Objective To assess the association between childbearing age and risk of offspring mortality in three birth cohort studies.

Setting Pelotas, Southern Brazil

Methods All hospital births which occurred in 1982 ( $n=6011), 1993$ $(n=5304)$ and $2004(n=4287)$ were identified and these infants were followed-up. Deaths were monitored through vital registration, visits to hospitals and cemeteries. The analyses were restricted to women younger than 30 years who delivered singletons $(72 \%, 70 \%$ and $67 \%$ of the original cohorts, respectively). Maternal age was categorised into three groups $(<16,16-19$, and 20-29 years). Additional analyses compared mothers aged $12-19$ and $20-29$ years. The outcome variables included fetal, perinatal, neonatal, post-neonatal and infant mortality. Potential confounders were family income, maternal education, maternal colour/race, marital status, parity, and pre-pregnancy body mass index. Crude and adjusted ORs were estimated with logistic regression models.

Results There were no interactions between maternal age and cohort year. After adjustment for confounding, the pooled ORs for infant death were 1.08 (95\% CI 0.42 to 2.78) for mothers younger than 16 years, 1.48 (1.03 to 2.12) for 16-19-year-olds, and 1.45 (1.01 to 2.07) for those aged 12-19, compared to a 20-29-year-old mothers. The excess risk was due to post-neonatal deaths.

Conclusion The slightly increased risk of post-neonatal mortality among the offspring of adolescent mothers suggests that social and environmental factors may be more important than maternal biologic immaturity. The possibility of residual confounding cannot be ruled out. 